\title{
A INFLUÊNCIA DA TRANSNACIONALIZAÇÃO DO DIREITO E DO NEOCONSTITUCIONALISMO NA ATUAÇÃO DA NOVA HERMENÊUTICA CONSTITUCIONAL
}

\begin{abstract}
Renata Albuquerque Lima
Pós-Doutora em Direito pela Universidade Federal de Santa Catarina - UFSC. Doutora em Direito Constitucional pela Universidade de Fortaleza - UNIFOR. Mestre em Direito Constitucional pela Universidade Federal do Ceará - UFC. Graduada em Direito pela UFC e em Administração de Empresas pela UECE. Professora do Programa de Pós-Graduação (Mestrado) em Direito da UNICHRISTUS. Professora Adjunta do Curso de Direito da Universidade Estadual Vale do Acaraú - UVA. Coordenadora do Curso de Direito da Faculdade Luciano Feijão - FLF. Advogada. E-mail: <realbuquerque@yahoo.com>.
\end{abstract}

\section{Átila de Alencar Araripe Magalhães}

Doutorando em Direito Constitucional pela Universidade de Fortaleza - UNIFOR. Mestre em Administração de Empresas pela Universidade de Fortaleza - UNIFOR. Especialista em Direito e Processo Tributários pela Universidade de Fortaleza - UNIFOR. Especialista em Direito Empresarial pela Universidade Estadual do Ceará - UECE. Professor de Direito Processual Civil da Universidade de Fortaleza - UNIFOR. Este autor registra o apoio da Universidade de Fortaleza como entidade financiadora das suas pesquisas, por meio da Diretoria de Pesquisa, Desenvolvimento e Inovação - DPDI. Advogado. E-mail: <atila@ leiteararipe.adv.br>.

\section{Thaís Araújo Dias}

Graduanda em Direito pela Universidade Estadual Vale do Acaraú - UVA. Bolsista do CNPQ. E-mail: <thais_araujo_dias@hotmail.com>.

\footnotetext{
Resumo: A globalização provocou diversas mudanças na tecnologia, na economia e na política, influenciando diretamente as relações sociais e, consequentemente, pautando a atuação do Estado. A transnacionalização, por sua vez, é um fenômeno que leva à superação de fronteiras nacionais. Nesse tocante, em um mundo global com corporações públicas e privadas transnacionais, inevitavelmente surgem problemas complexos de diversos matizes, em especial de interpretação da norma jurídica nacional e estrangeira, o que justifica a premente necessidade de se estudar e de se aprofundar na temática. Diante dessas premissas, este artigo analisa a importância da nova hermenêutica para a resolução de conflitos decorrentes da transnacionalização do direito em tempos de globalização, sem que se fragilizem os princípios do movimento do neoconstitucionalismo. Para tanto, por meio de pesquisa bibliográfica, retomam-se conceitos, numa perspectiva histórica de diferentes doutrinadores acerca da transnacionalização, da hermenêutica e do neoconstitucionalismo. Outrossim, o trabalho
} 
analisa os desafios do direito e do neoconstitucionalismo frente às complexidades da sociedade sem fronteiras, bem como defende a relevância da hermenêutica para o ordenamento jurídico como instrumento de resolução de conflitos transnacionais.

Palavras-chave: Transnacionalização. Neoconstitucionalismo. Nova hermenêutica constitucional.

Sumário: 1 Introdução - 2 Perspectiva histórica da globalização e a sua incidência nas relações transnacionais e na soberania estatal - $\mathbf{3}$ Neoconstitucionalismo e os desafios constitucionais da globalização - 4 A relevância da hermenêutica para o ordenamento jurídico como instrumento de resolução dos conflitos transnacionais - $\mathbf{5}$ Conclusão - Referências

\section{Introdução}

Em tempos de globalização, as distâncias foram reduzidas, resultando em mudanças nos mais diversos âmbitos. A tecnologia, a economia mundial, a política, a cultura e as relações sociais sofreram e sofrem contínuas influências desse fenômeno, o que tem impactado na atuação do Estado em relação à sociedade. Todavia, não se tem como falar em globalização sem se analisar o fenômeno da transnacionalização. Trata-se, em miúdos, de um processo de superação das fronteiras nacionais de um dado Estado internacional.

Os agentes que perpassam fronteiras de determinado país podem ser entes públicos ou privados. Diante dessa complexidade de relações internacionais entabuladas por esses agentes, surgem, inevitavelmente, demandas com repercussões transnacionais. 0 surgimento de organismos plurinacionais permite também a criação de novas relações, por vezes tutelados por estes. Com efeito, o Estado tem enfrentado problemas na resolução desses conflitos internacionais decorrentes da sociedade complexa da atualidade. Essa situação é vista, por muitos, como o principal fator das crises presentes no Estado Constitucional Moderno.

Esse Estado Moderno tem como características a soberania interna e o monopólio da produção legislativa. Essas características são denominadas de "monismo estatal". Nesse vértice, essa forma de organização estatal vem sendo questionada, visto que a supremacia interna e a independência da ordem externa não são suficientes para acompanhar as transformações sociais. Antonio José Avelã Nunes (2011) afirma que a ideologia neoliberal vislumbra e defende um Estado mínimo e, por meio da globalização dos mercados, esses pensamentos ganham reforço, pois o fenômeno mercantil é um fator preponderante para a perda de soberania dos Estados nacionais, ou seja, o modelo tradicional de Estado constitucional moderno não se mostra mais adequado para lidar com 
os fenômenos decorrentes da globalização e da transnacionalização dos entes públicos e privados.

Impende ser dito que o fenômeno da globalização não está restrito ao âmbito econômico. Conforme mencionado, a globalização atinge diretamente a tecnologia, a política, a cultura e as relações sociais; entretanto, não se limita a elas. Incluem-se as relações ratificadas entre nações por meio de tratados e protocolos internacionais que geram novas situações, embora, por vezes reguladas pelo próprio teor do documento, necessitam ser analisadas para que não haja inobservância entre o ordenamento jurídico interno e o advento desses respectivos documentos. Já na perspectiva privada, uma empresa que tem como finalidade social a exploração de uma atividade ligada à tecnologia, por exemplo, não fica adstrita aos limites territoriais onde se localiza a sua ou as suas sedes. Os negócios são fechados para além-fronteiras. Trata-se de uma atuação transnacional. Assim, os consectários das relações jurídicas que albergam as atividades empresariais não podem ficar sem uma análise mais detida do direito. Nesse sentido, a análise tradicional dessas relações jurídicas não oferece resolução para os problemas daí decorrentes. Portanto, a revisão dessas análises é premente.

Se surge uma altercação decorrente de uma desavença ou de uma quebra contratual, relativamente a negócios firmados por entes públicos ou privados situados em países diversos, cabe aos Estados encontrar meios de resolver esses conflitos, sem, contudo, comprometer a soberania e a independência dos países onde a lide se iniciou, onde o contrato foi firmado ou onde a obrigação deva ser prestada ou satisfeita. Essa seara traz à discussão a consecução de direitos que ultrapassem limites nacionais. Seria, então, objeto do direito internacional? Philip Jessup apresentou, por meio de sua obra Transnational Law, um conceito que compreende o direito internacional, porém não se limita a este. Trata-se do direito transnacional. Para o autor, o direito internacional sugere uma preocupação apenas com relações entre nações; já o direito transnacional aplica-se à complexa comunidade internacional, compreendendo desde o indivíduo (JESSUP, 1965).

Um direito transnacional bem desenvolvido, por certo, consegue estancar esses tipos de conflito. Com a finalidade de abrandar a problemática exposta, pode-se pensar como solução a criação de uma constituição una, que compreenda normatividade, que possa influir nos diversos Estados. Entretanto, a complexidade da multicultarilidade e das individualidades de cada nação não permite a efetivação desta. Andrea Ântico Soares e Viviane Rigoldi (2013) afastam essa ideia da criação de uma constituição planetária por motivo de incompatibilidade entre os países do globo, em termos de historicidade dos fenômenos culturais, costumes e ideologias. 
Portanto, afastando a ideia mirabolante de uma única ordem constitucional planetária, a alternativa que surge é trabalhar para se desenvolver constituições coerentes com o modelo de Estado Democrático e Social de Direito, que tragam em seu bojo fundamentos universais de democracia e de direitos humanos. A tensão posta é como se criar instrumentos que possam viabilizar esse intento ao mesmo tempo em que se adotam fórmulas padronizadas de solução de conflitos de caráter transnacional sem fragilizar a supremacia constitucional local.

Nesse sentido, inevitável a indagação: seriam os princípios hermenêuticos a solução para essa problemática?

Obviamente que a resposta a essa indagação não se mostra simplória. Pelo contrário, trata-se de uma reflexão com repercussões em diversas searas do conhecimento. Logo, não se tem a pretensão de responder a essa problemática, mas de analisar a importância da hermenêutica para uma harmonização de ordenamentos jurídicos tão complexos, distintos e peculiares, como os dos países componentes do Planeta Terra. A propósito, Nagib Slaibi Filho (2011, p. 1) sustenta que a hermenêutica é "a ciência que fornece a técnica para a interpretação (...); é o ato de apreensão da expressão jurídica, enquanto a aplicação da norma é fazê-la incidir no fato concreto nela subsumido".

A concepção de hermenêutica não permaneceu inata e se desenvolve de acordo com o contexto. No início da evolução da hermenêutica jurídica, o brocado in claris cessat interpretatio foi difundido como afirmativa sobre a não necessidade da interpretação de uma lei clara. Tal difusão ainda se faz presente, em especial, na cultura ocidental; entretanto, a literalidade normativa não deve ser afastada de uma compreensão qualificada, ou seja, uma interpretação qualificada (MEDEIROS, 2000). Para Paulo Bonavides (2000), a "nova" hermenêutica, por sua vez, não se atém à interpretação literal da norma por motivo simples: a norma constitucional é complexa. Portanto, deve ser compreendida além da literalidade do texto.

Nesse sentido, este artigo se propõe a analisar como a nova hermenêutica pode contribuir para a resolução de conflitos decorrentes da transnacionalização do direito, em tempos de globalização, sem que se fragilizem os princípios do movimento do neoconstitucionalismo, em especial, a soberania estatal.

\subsection{Itinerário metodológico}

Para a consecução do objetivo proposto, foi eleito um itinerário metodológico que se iniciou com a imersão em fontes bibliográficas. Realizou-se, a princípio, uma busca livre sobre os termos transnacionalização, neoconstitucionalismo e nova hermenêutica em livros disponíveis em bibliotecas físicas e virtuais. Esse 
movimento foi importante para delimitar o objeto de estudo e dimensionar a complexidade da temática enquanto campo de pesquisa e prática das ciências jurídicas, particularmente quando da associação entre esses três temas.

Visando ampliar a qualidade no critério de seleção de artigos, acessou-se o portal de periódicos da CAPES. Utilizaram-se como estratégias de busca os termos independentes transnacionalidade, transnacional, nova hermenêutica constitucional, nova hermenêutica e neoconstitucionalismo. Em seguida, prosseguiu-se com cruzamentos por meio do operador boleano AND. A opção por esse operador justifica-se em razão do objeto de estudo não referir-se a um único termo enquanto categoria teórica, mas a intercessão daqueles. Não se delimitou filtro temporal, assim como se realizou a busca em todas as línguas. A busca foi realizada considerando o filtro "e(exato)". As estratégias de busca e os resultados dos estudos identificados encontram-se no Quadro 1.

QUADRO 1

Sistematização da busca de artigos científicos no portal de periódicos da CAPES realizada em 27 de fevereiro de 2018

\begin{tabular}{|c|c|c|c|c|}
\hline $\begin{array}{l}\text { Portal } \\
\text { CAPES }\end{array}$ & Termos utilizados & Resultados & $\begin{array}{c}\text { Estudos } \\
\text { selecionados }\end{array}$ & $\begin{array}{c}\text { Estudos } \\
\text { completos } \\
\text { disponíveis }\end{array}$ \\
\hline & Transnacionalidade & 00 & - & - \\
\hline & Transnacional & 8.246 & - & - \\
\hline & $\begin{array}{c}\text { Nova hermenêutica } \\
\text { constitucional }\end{array}$ & 04 & - & - \\
\hline & Nova hermenêutica & 39 & - & - \\
\hline & Neoconstitucionalismo & 07 & - & - \\
\hline & $\begin{array}{l}\text { Transnacional AND } \\
\text { nova hermenêutica }\end{array}$ & 01 & 01 & 01 \\
\hline & $\begin{array}{c}\text { Neoconstitucionalimo } \\
\text { AND nova } \\
\text { hermenêutica }\end{array}$ & 04 & 03 & 03 \\
\hline & $\begin{array}{c}\text { Transnacional AND } \\
\text { neoconstitucionalismo }\end{array}$ & 04 & 03 & 03 \\
\hline
\end{tabular}

Fonte: Elaborado pelos autores. 
A busca com termos "e-exatos", porém independentes, permitiu-nos optar por transnacional, e não transnacionalidade, já que não houve identificação de artigos para o segundo, bem como delimitar a busca ao termo nova hermenêutica, já que a busca independente por nova hermenêutica constitucional foi restritiva quando comparada com a primeira. Desse modo, seguiu-se com os cruzamentos "transnacional AND nova hermenêutica", "transnacional AND neoconstitucionalismo" e "nova hermenêutica AND neoconstitucionalismo". A partir desses cruzamentos, foram identificados 10 artigos, sendo que dois se repetiam na base de dados e um foi excluído por abordar foco distinto do interesse dos autores.

De modo que, do total encontrado, sete artigos foram selecionados por colaborarem com a discussão do objeto em estudo. Todos os sete artigos encontravam-se disponiveis e completos. Logo, os critérios de seleção dos estudos para aprofundamento deste artigo foram artigos que articulassem pelo menos dois dos três termos teóricos que definem o objeto e que se encontravam disponível na íntegra no Portal CAPES, independentemente da língua.

Considerando o itinerário metodológico, desenhamos uma estrutura para este artigo em três tópicos, a par da introdução e da conclusão, a saber: perspectiva histórica da globalização e a sua incidência nas relações transnacionais e na soberania estatal; neoconstitucionalismo e os desafios constitucionais na globalização; e a relevância da hermenêutica para o ordenamento jurídico como instrumento de resolução dos conflitos transnacionais.

\section{Perspectiva histórica da globalização e a sua incidência nas relações transnacionais e na soberania estatal}

A globalização estreitou inúmeros vínculos no curso da história, inclusive entre nações e Estados soberanos distintos. A intensificação desse fenômeno ocorreu após a Segunda Guerra Mundial, a qual representou um marco na ampliação do acesso aos meios de comunicação e aos transportes e, em especial, uma maior interação entre comércios de países distintos (STELZER, 2011).

Percebe-se que esse processo globalizante ultrapassa fronteiras nacionais, envolvendo e integrando comunidades e organizações numa combinação espaçotempo que permite maior conectividade (LIMA, 2014). É nesse contexto que surge a transnacionalização, ou seja, no seio da globalização, configurando assim fenômenos indissociáveis (STELZER, 2011).

A fenomenologia da transnacionalização tem sua intensificação, assim como a globalização, a partir do pós-guerra, quando há a expansão do capital, a 
desterritorialização e, principalmente, o surgimento de operações oriundas do novo caráter mundial no âmbito econômico-comercial (BECK, 1999). A nova natureza mercantil, agora internacionalizada, acarreta distintas mudanças na sociedade, que passa a influenciar não somente na tomada de decisão do seu Estado, mas, também, da coletividade deste.

Constitui-se, pois, a transnacionalização fenômeno reflexivo da globalização que favorece a desterritorialização das relações político-sociais, fortalecidas pelo sistema econômico capitalista, que articula o ordenamento jurídico mundial à margem das soberanias dos Estados. Os termos se distinguem no sentido de que, enquanto a globalização exprime a ideia de conjunto, de globo, mundo sintetizado como único, a transnacionalização alinha-se à concepção de Estado permeável, fato este que põe o ente estatal em relativa suscetibilidade (STELZER, 2011). Para esta mesma autora, "enquanto a globalização é o fenômeno envolvedor, a transnacionalidade é a nascente de um terceiro espaço, inconfundivel com o espaço nacional ou internacional" (p. 21).

É perceptível o crescimento de pesquisas em distintas áreas do conhecimento cujos objetos de estudos estão voltados para a globalização, reverberando inúmeras teorias na busca de esclarecerem os mitos e significados desse fenômeno que visam desmitificar os desafios gerados para as sociedades nacionais. Dessa constatação, inferem-se os reflexos da globalização em diversas áreas/setores. Esse fenômeno global criou desafios para as sociedades nacionais, visto que os intercâmbios culturais, sociais e econômicos originaram novas relações, as quais ainda se desconhece grande parte de seus resultados. No âmbito do direito, não é diferente. A globalização trouxe desafios para o ordenamento jurídico (SILVA, 2011).

É nesse contexto da globalização que o termo transnacionalidade ganha força e se expressa em vários campos do conhecimento. Registros dão conta que o primeiro autor a tratar da transnacionalização do direito foi Philip Jessup, em 1965, em sua já referida obra Transnational Law, na Universidade de Yale. Para esse pesquisador, o uso do direito transnacional forneceria uma fonte mais abundante de normas com que se guiar. Consequentemente, os direitos internacionais público e privado começam a perder espaço e importância diante dessa nova seara do direito que começa a ser descortinada. A ocorrência desse fenômeno justifica-se pelo fato de o direito transnacional incluir "todas as normas que regulam atos ou fatos que transcendem fronteiras nacionais" (JESSUP, 1965, p. 12).

Harold Hongju Koh (2006), também pesquisador da Universidade de Yale, compreende que o direito transnacional é uma tendência emergente devido à sua 
ascensão e, com isso, justifica a relevância do estudo deste que é um direito híbrido entre o direito doméstico e o direito internacional.

o tirocínio de Jessup elucida que o direito transnacional envolve todo o direito que regula ações ou eventos que ultrapassam fronteiras nacionais. Inclui, portanto, os direitos internacionais público e privado, assim como estão outras regras que não se encaixam diretamente nessas tipologias. Perpassa, assim, o Estado e supera a dicotomia público e privado. Ressalta-se que essa intelecção de Jessup será tomada como referência para o presente estudo.

A relevância da conceituação de direito transnacional e sua diferenciação de direito internacional devem-se ao fato de que, a partir do entendimento dessas concepções, se pode analisar uma problemática sob a ótica de um ramo do direito ou do outro. As situações que são abarcadas pelo direito transnacional compreendem aquelas em que há o envolvimento de indivíduos, pessoas jurídicas de direito público e de direito privado, ou seja, uma vasta variedade de situações transnacionais. Nesse sentido, Jessup demonstra a importância do termo apropriado a ser utilizado em cada contexto: "Parte da dificuldade em analisar os problemas da comunidade mundial e o direito que os regula consiste na falta de uma palavra apropriada para designar as normas em discussão" (JESSUP, 1965, p. 11).

Entende-se que, como fruto da magnitude das questões econômicas, a soberania dos Estados-Nações foi e permanece sendo fragilizada. A volatilidade das relações transnacionais e a consequente nova dimensão reduzida da tutela estatal fragiliza o Estado constitucional moderno, visto que o seu pilar no âmbito político é a soberania exercida territorialmente (CRUZ; BODNAR, 2010). É nítida, portanto, a interferência da economia na ciência do direito. Assim, embora se considerem campos autônomos do conhecimento, é perceptível uma clara interação entre essas ciências diante das novas relações decorrentes da fenomenologia transnacional.

No tocante ao neoliberalismo, Alexandre Morais Rosa (2011) aponta ser uma tendência natural que a economia instrumentalize o direito. Explica-se: é que o ordenamento jurídico naturalmente sofre influências do mercado e, nesse sentido, esse fenômeno acaba por contribuir negativamente em relação à soberania estatal, visto que o Estado fica exposto às intempéries do mercado.

É válido ressaltar, entretanto, que o Estado não desaparece com a transnacionalidade ou mesmo com as influências da economia no direito em tempos de mercados globais, mas, inegavelmente, constata-se uma relativa fragilização, de maneira que não se reconhece mais o ente político-jurídico construído sobre as suas premissas clássicas. Nesse diapasão, o Estado Moderno passa a contestar a sua invencibilidade soberana de outrora e a sua capacidade 
exclusiva de ordenamento dos relacionamentos entre os sujeitos que o cercam (STELZER, 2011).

Norberto Bobbio (1986, p. 187-188), ao se referir ao poder estatal, anuncia que:

Estando este supremo poder de Direito em via de extinção, faz-se necessário agora, mediante uma leitura atenta dos fenômenos políticos que estão ocorrendo, proceder a uma nova síntese político-jurídica capaz de racionalizar e disciplinar juridicamente as novas formas de poder, as novas "autoridades que estão surgindo".

Acrescenta o supracitado autor que o golpe maior veio das comunidades supranacionais, as quais visam limitar a soberania interna e externa dos EstadosMembros. Esta tensão vivida pelo Estado Constitucional Moderno, como modelo de construção político-jurídica frente à complexidade da transnacionalização, requer uma análise contextual. Deve ser considerado, nesse enfoque, que esse modelo de Estado foi teorizado em uma época de extrema limitação tecnológica e se consolidou num momento em que a comunidade política se definiu a partir da sujeição comum a um poder político, que exerceu sua autoridade num âmbito territorial e sobre aqueles que nele se situavam. Esse vínculo de unidade e sujeição não expressa as atuais formas de organizações e instituições e é incapaz de dar vazão às demandas transnacionais. Por fim, convém dizer que esse modelo tradicional de Estado Constitucional não se encontra, necessariamente, totalmente ultrapassado (CRUZ; BODNAR, 2010).

Por esta lente, o conceito de soberania apresenta-se em avançado estágio de desgaste conceitual e prático. Em contraposição, observa-se a intensificação das relações sociais caracterizadas não mais por uma relação direta (inter) ou via Estado (inter-nacional), mas pelo transpasse estatal (transnacional). É nesse cenário que emerge a transnacionalização, desnudando a já referida desterritorialização dos relacionamentos político-sociais que articulam o ordenamento jurídico mundial à margem das soberanias dos Estados (STELZER, 2011).

A discussão que se pretende empreender neste texto é no sentido de se colaborar com a discussão sobre o direito transnacional. Nesse sentido, Jessup (1965) alerta que é preciso evitar refletir sobre o direito transnacional unicamente em termos de um dado foro particular, pois, reconhecidamente, há tribunais que não seguem os seus próprios regimentos, as leis locais, as leis nacionais e muito menos as leis internacionais, mas adotam soluções alternativas de resolução de conflitos, como a composição (meio extralegal ou metajurídico); assim, a solução 
para o problema muitas vezes sequer se encontra prevista no ordenamento jurídico.

As instituições, no âmbito do Estado-Nação, diante do fenômeno da globalização, têm sido impactadas diretamente. Esses impactos advêm da maleabilidade, da flexibilidade, da fluidez do Estado moderno, o qual não consegue adaptar-se às vicissitudes da ambiência mercadológica em que se encontra (FARIA, 2002). A flexibilização das normas, por influência direta do mercado, tornou o Estado menos interventor e com menos potencial de tutela, embora se saiba que o Estado permanece legislando incomensuravelmente.

Seguindo os pilares do Estado transnacional, o direito transnacional possui como máxima a desterritorialização. Essa característica é inerente ao próprio conceito de direito transnacional, ou seja, o “direito-além-da-fronteira”, que não encontra delimitação (CRUZ; BODNAR, 2010). Essa circunstância molda um cenário distinto do tradicional Estado Constitucional Moderno, o qual, como fruto do movimento do neoconstitucionalismo, traz como princípios a democracia e a soberania territorial para, de forma coercitiva, limitar o poder estatal visando à consecução das ânsias sociais que possuem como ápice os direitos fundamentais.

É fato que o fenômeno da transnacionalização ocasionou o surgimento de novas relações que perpassam os limites territoriais delimitados pelo poder estatal. A complexidade da sociedade mundial é ascendente, já que, com o aumento e intensificação dessas relações, urge, crescentemente, a necessidade de regulamentá-las. Cabe ao ordenamento jurídico buscar estratégias para tutelar os novos conflitos da sociedade oriundos dessas novas relações.

O desenvolvimento das organizações transnacionais, por si só, gera o relativismo da soberania, pois, por meio dessas alianças, os Estados estão diante de normas que tutelam distintas nações, com exígua preocupação em relação às particularidades locais. Tal fato reduz a independência estatal, pois o Estado Constitucional Moderno admite, nesses casos, controle dos seus atos por organismos internacionais e, ao mesmo tempo, contrai obrigações externas advindas dos tratados internacionais (FERNANDES; SANTOS, 2014).

O desafio do ordenamento jurídico do Estado global e transnacional é justamente criar um sistema de cooperação internacional. Isso se justifica, uma vez que, diante da sociedade transnacional, há uma complexa rede de interação entre sujeitos pertencentes a sistemas nacionais distintos, em âmbitos privado e público, sendo necessário observar as peculiaridades de cada sistema nacional. E essa complexidade da sociedade transnacional é atribuída, em parte, às forças econômicas e políticas regidas por elites governamentais e não governamentais (BRAILLARD, 1979). 


\section{Neoconstitucionalismo e os desafios constitucionais da globalização}

É fato que as constituições hodiernas passam por desafios postos pelo fenômeno da globalização. Para que se possa compreender a causa desses obstáculos, torna-se mister conceituar constituição. Não há uma conceituação plena, mas José Afonso da Silva (2014), de forma clara e objetiva, a define como "lei fundamental de organização do Estado" (p. 39), pois cabe a esta estruturar e delimitar os seus poderes políticos.

Diante do conceito apresentado, é possível observar que a tutela de uma constituição é restringida ao limite territorial do Estado no qual ela se encontra sob vigência. O estabelecimento da forma de Estado, assim como da forma de governo, a organização dos órgãos públicos, os limites da atuação dos governantes visando à efetivação dos direitos e garantias fundamentais, organização social e econômica são assuntos, entre muitos outros, tutelados pelas constituições federais (PEÑA, 2004).

Há uma evidente relação entre a Constituição Federal e o Estado. Este se organiza e se pauta nos esquadros legais daquela. A primeira traz em seu bojo os contextos social, cultural e econômico da sociedade que a criou. José Joaquim Gomes Canotilho (2017) contribui para esse raciocínio ao afirmar que a Constituição é a obra fundacional do Estado.

As constituições vigentes possuem atributos distintos das primeiras cartas constitucionais. 0 movimento denominado de constitucionalismo surge com a necessidade de limitar o poder dos governantes e, consequentemente, alcançar um Estado que atenda aos anseios da população. A Carta Magna Libertatum foi o primeiro documento escrito que limitou o poder do monarca e protegia a população de decisões abusivas, buscando o ideal de igualdade para cidadãos ingleses (DALLARI, 2005).

Por volta da metade do século XX, em especial após a Segunda Guerra Mundial, houve uma grande preocupação internacional com a proteção dos direitos humanos. 0 mundo estava comovido não somente com os mortos em combate, mas também se encontrava assustado com o genocídio dos judeus liderado pelo governo alemão (SILVA et al., 2014). O questionamento sobre a legalidade e a legitimidade de tais atos foi fundamental para a construção de constituições que buscassem novos ideais.

Luiz Roberto Barroso (2006, p. 3) reitera a importância dos marcos históricos para esse novo direito constitucional e explana as consequências dessa nova vertente do constitucionalismo: 
A reconstitucionalização da Europa, imediatamente após a $2^{\text {a }}$ Grande Guerra e ao longo da segunda metade do século XX, redefiniu o lugar da Constituição e a influência do direito constitucional sobre as instituições contemporâneas. A aproximação das ideias de constitucionalismo e de democracia produziu uma nova forma de organização política, que atende por nomes diversos: Estado democrático de direito, Estado constitucional de direito, Estado constitucional democrático (...).

Luiz Roberto Barroso (2006) demonstra ainda a importância do processo de reconstitucionalização da Europa ocorrido ao longo da segunda metade do século $X X$, que influenciou as organizações constitucionais do Ocidente. Foi durante esse período que surgiu o neoconstitucionalismo, no qual a Constituição ultrapassou o seu teor, até então normativo, e passou a participar ativamente de mudanças institucionais e políticas, além de fortalecer a participação popular.

O neoconstitucionalismo, assim, tem como escopo uma nova forma de interpretação do direito. Esse movimento destaca-se por agregar novos valores nos textos constitucionais.

Importa-se destacar, entretanto, que o neoconstitucionalismo trouxe consigo algumas críticas. O autor Aldunete Liziana (2010), na obra Aproximacón Conceptual y Crítica al Neoconstitucionalismo, questiona o próprio termo por tratar-se de um neologismo referente ao novo constitucionalismo. Dessa forma, esse movimento deveria preservar o caráter postulatório do constitucionalismo de destinação a organização de poderes, critérios de legitimidade e a relação destes com a lei; entretanto, afirma que:

(...) nada de ello ocurre, sin embargo, en el caso del término en análisis. no describe un movimiento como programa político 0 unos objetivos políticos a los cuales pueda adherir alguien que se declara "neoconstitucionalista", sino que, en primera línea, se usa para describir ciertos fenómenos o prácticas institucionales de los estados constitucionales -en su inicio, europeos- tras la segunda Guerra mundial (p. 80).

Seguindo essa perspectiva das críticas ao neoconstitucionalismo, a doutrina positivista destaca três pontos: constituições rígidas com alta densidade normativa e a panconstitucionalização do direito; ativismo jurídico em possível detrimento dos outros poderes; e abordagem axiológica - preferência pelos princípios e a superação do positivismo (LIZIANA, 2010; VIEIRA JÚNIOR, 2014). 
No contexto da panconstitucionalização, Daniel Sarmento, em suas obras, alerta sobre a perspectiva negativa de uma constitucionalização que possa vir a se estender a todo o ordenamento jurídico. Já no que concerne o exacerbado ativismo jurídico, o mesmo autor afirma a prejudicabilidade de excessiva judicialização, visto que, diante de um regime democrático, deve-se ter, como representação principal, aqueles representantes escolhidos pelo povo (SARMENTO, 2007; 2009). Por fim, na perspectiva da abordagem axiológica dos princípios, a crítica é realizada pelos positivistas, já que, na visão destes, o direito é uma ciência sem lacunas, e o próprio ordenamento jurídico supre as necessidades do processo (VIEIRA JÚNIOR, 2014).

As críticas não fragilizam a significativa relevância do neoconstitucionalismo no que concerne o estado constitucional, ao mesmo tempo em que há a crítica dos positivistas ao caráter axiológico atribuído às constituições no pós-Segunda Guerra. Há também os aspectos positivos oriundo dessa característica fruto do neoconstitucionalismo. É através do teor axiológico que a Constituição conseguirá efetivar os seus princípios basilares e norteadores da sociedade que a mesma resguarda, pois permite uma contextualização social e temporal.

Norberto Bobbio (2006) demonstra uma singularidade do neoconstitucionalismo. $\mathrm{O}$ autor compreende que, na vigência do positivismo, a preocupação estava restrita à aplicação da lei, enquanto no Estado Constitucional Moderno, seguindo a principiologia do neoconstitucionalismo, almeja a eficácia da normatividade e a aplicabilidade na sociedade. Importante ressaltar que, após o neoconstitucionalismo, a nova forma de organização política assume distintas nomenclaturas: Estado Constitucional Moderno, Estado Constitucional de Direito, Estado Democrático de Direito, entre outros (BARROSO, 2006).

O Estado Constitucional Moderno constitui-se em um organismo que tem como alicerces a soberania interna e o monopólio da produção legislativa. Essa forma de organização estatal vem sendo questionada, visto que os ideais de supremacia no âmbito interno e independência na ordem externa não acompanharam as transformações sociais (FERNANDES; SANTOS, 2014). Na perspectiva da soberania externa, o Estado perde seu poder em detrimento de "supersoberania supranacional” (PASOLD; FERRER; CRUZ, 2016). Eros Grau (2011) denomina tal fenômeno como o processo de "desterritorialização" da soberania, que é fruto direto da transnacionalidade.

As realidades individualizadas, ou seja, as realidades locais de cada Estado, já não são as únicas que necessitam da atenção do legislador e do jurista. A nova realidade tem se tornado cada vez mais universal e, como consequência, o direito nacional está, embora de forma gradativa, tornando-se internacionalizado e transnacionalizado (AGUADO, 2006). Um exemplo dessa transnacionalização é 
a participação do Brasil, por meio da Emenda Constitucional no 45, no Tribunal Penal Internacional. A adesão brasileira aos tratados de direitos humanos também pode ser considerada, ainda que de maneira tímida, uma promissora abertura da Constituição Federal de 1988 (CUNHA, 2010).

Ademais, a busca pelo combate do tráfico internacional de drogas, a preservação do meio ambiente por órgãos internacionais e, em especial, a valorização dos direitos humanos são ações positivas já oriundas de relações entre países distintos. A ciência jurídica, assim como as demais ciências, devem permanecer sob constante análise e reflexão do seu objeto de estudo. Essa situação torna-se mais necessária no âmbito jurídico diante da maleabilidade das relações. Assim, é preciso a conciliação entre os novos objetos de estudo e o método coerente a ser utilizado. Os novos métodos que devem ser buscados pelo sistema jurídico, a partir do fenômeno da globalização, devem ser apontados para o mercado internacional, crises econômicas, blocos econômicos, relação entre homem e mercado, entre outros (HÄBERLE, 2007). Assim, diante das influências da globalização em diversos âmbitos e a impossibilidade de um país e seu povo se desenvolverem de maneira isolada, é necessário repensar em um direito e em uma hermenêutica harmônicos com as novas relações e desafios oriundos da globalização.

\section{A relevância da hermenêutica para o ordenamento jurídico como instrumento de resolução dos conflitos transnacionais}

Os organismos e tratados internacionais apresentam papel relevante frente à busca de solução para os conflitos transnacionais. Um exemplo prático do disposto é a carta da Organização das Nações Unidas (ONU), que prevê em seu artigo $2^{\circ}$, §3ำ, que os membros da respectiva organização deverão resolver suas controvérsias no âmbito internacional de forma pacífica, respeitando a paz e a segurança internacional. Destarte, tal documento também afirma que as partes, visando evitar conflitos que possam vir a fragilizar a paz internacional, buscarão solucionar suas controvérsias por meio de negociações, conciliações, arbitragens ou outros recursos que objetivem a solução de forma pacífica (ONU, 1945).

As soluções pacíficas diante das controvérsias internacionais classificam-se em categorias amistosas e coercitivas. As amistosas compreendem a diplomacia e meios jurídicos estabelecidos, enquanto a coercitiva se refere à aplicabilidade de sanções (ACCIOLY, 1954). O propósito do presente estudo não é afastar a incidência dos organismos e dos tratados internacionais multilaterais como meios 
de solução dos litígios transnacionais, mas, sim, ressaltar os métodos da nova hermenêutica e a aplicabilidade desta como mais uma possibilidade de solucionálos sem que haja o afastamento, de forma incisiva, da soberania estatal daqueles envolvidos no litígio.

No que concerne ao Estado brasileiro, a relevância dos tratados internacionais que possuem teor de direitos humanos é destacada através da corrente doutrinária e pacificada pelo Supremo Tribunal Federal, os quais compreendem que esses documentos possuem força supralegal - inferior à Constituição Federal, mas acima das demais leis infraconstitucionais (MAZZUOLI, 2013). Nessa perspectiva, devem ser agregados no momento da aplicação da técnica interpretativa os limites previstos nos referidos documentos.

No âmbito do direito, a interpretação é ato necessário para a efetiva e coerente aplicação da norma jurídica. Jorge Miranda (2000, p. 258) enfatiza a importância do instrumento da interpretação na ciência jurídica ao afirmar que "não é possível a aplicação sem interpretação, tal como esta só faz pleno sentido posta ao serviço da aplicação". Paulo Bonavides também compreende a necessidade da relação entre a norma e a interpretação: "Não há norma jurídica que dispense interpretação" (BONAVIDES, 2000, p. 398).

O marco histórico que distingue de forma mais concisa a hermenêutica da interpretação ocorre durante o século XIX por meio da contribuição de Friedrich Schleiermacher. Até então, os dois termos eram vistos como indissociáveis. 0 referido autor propõe a utilização de um método científico que ultrapassasse a interpretação literal (MAGALHÃES FILHO, 2011).

O novo método seria constituído por buscar compreender o pensamento do autor. Esse instrumento possuiria cunho subjetivo e comparativo. Na perspectiva do direito, é possível exemplificar o cunho subjetivo por meio da necessidade de compreender a vontade do legislador. $\mathrm{Na}$ análise comparativa, a investigação se dá na compreensão da vontade do legislador ao elaborar o dispositivo e comparálo com o texto da norma jurídica. Esse método comparativo buscava identificar, de maneira objetiva, expressões expostas pelo autor na literalidade do dispositivo. Tal método contrabalanceia a vontade do autor e a interpretação da norma no aspecto textual (TORRES; SILVA, 2014).

É fato que a hermenêutica é relevante para a ciência do direito. Na seara jurídica, é preciso compreender que a hermenêutica é utilizada pelos operadores do direito para designar:

A doutrina dos métodos ou a teoria científica da interpretação pela qual se realiza o ensino das técnicas ou das regras e procedimentos 
de interpretação, a fim de que seja possivel a manutenção do controle metódico da divergência entre os textos normativos e as normasdecisão; em outros termos, a fim de que seja possivel legitimar-se a rejeição da responsabilidade política em função de decisões cada vez mais abstratas na elaboração dos textos de normas em função das decisões práticas (SILVA, 2009, p. 1-2).

Limongi França (2009, p. 19) aloca a hermenêutica como parte da ciência jurídica e elenca o seu objeto de estudo ao afirmar que a "hermenêutica se refere à parte da ciência jurídica que tem por objeto o estudo e a sistematização dos processos, que devem ser utilizados para que a interpretação se realize, de modo que o seu escopo seja alcançado da melhor maneira".

Do exposto, infere-se que a hermenêutica é uma teoria que visa à interpretação e percepção do texto normativo para além das palavras. A ideia de que, quando o texto é claro, é vedada a interpretação encontra-se obsoleta. Essa compreensão é um questionamento realizado diante da hermenêutica jurídica clássica. Carlos Maximiliano (2008) afirma que não somente a norma individualizada deve ser analisada, mas o seu contexto, os demais dispositivos que abordam o assunto tutelado e, em especial, a Constituição Federal. Embora, algumas vezes, as normas aparentemente sejam claras, é sempre necessária uma compreensão mais profunda, indo além da literalidade e da individualidade. 0 autor reforça essa necessidade através da passagem seguinte:

Se às vezes à primeira vista se acha translúcido um dispositivo, é pura impressão contingente, sem base sólida. Basta recordar que o texto da regra geral quase nunca deixa de pressentir a existência de exceções; logo, o alcance de um artigo de lei se avalia confrontando-o com outros, isto é, com aplicar o processo sistemático de interpretação (MAXIMILIANO, 2008, p. 31 - grifos originais).

A hermenêutica jurídica clássica e metodológica foi influenciada pelos ideais de Schleiermacher e Dilthey. A interpretação com foco do direito privado, em especial, no âmbito do Código Civil, é uma característica evidente na hermenêutica jurídica clássica. A antinomia não era admitida, pois, recordando as ideias de Savigny, a interpretação deve ser realizada nos âmbitos gramatical, lógico, sistemático e histórico. Esse foco em um sistema fechado (direito civil) e a restrição no que concerne à interpretação direcionaram a hermenêutica jurídica clássica para fatos específicos e, consequentemente, sofre críticas (TORRES; SILVA, 2014).

No centro do Estado Democrático de Direito encontra-se a Constituição Federal. Essa mudança no cenário estatal é oriunda do movimento denominado 
neoconstitucionalismo. Como exposto anteriormente, esse movimento tornou a Constituição o guia do ordenamento jurídico, abordando os ensejos sociais e limitando o poder estatal. A Carta Magna consolidou sua importância após o lluminismo e expandiu sua força normativa.

A Constituição compreendida como uma carta política é consolidada através do Estado Social. Essa forma de organização estatal demonstra-se inovadora diante do liberalismo clássico. Por haver uma preocupação com os anseios populares e com as necessidades sociais, o Estado Social rompe com os princípios vigentes até então, passando a proporcionar à sua população direitos para além dos garantidos pelo Estado Liberal, que compreendia somente os direitos individuais. Ademais, a exacerbada valorização pela normatização estatal decai diante dos aspectos sociais e políticos que os novos textos constitucionais requerem (FONTENELE JÚNIOR, 2014).

É fato que, com as mudanças ocorridas na forma de atuação do Estado, que passa a ser positiva, e a nova caracterização da Constituição, a hermenêutica jurídica clássica criada por Savigny, que direcionava seu estudo para o ordenamento jurídico fechado, já não possui a mesma efetividade. A necessidade de compreender os institutos dessa nova perspectiva de Constituição requer uma nova hermenêutica, também denominada como nova hermenêutica constitucional, visando atuar em prol dos anseios sociais.

O autor Paulo Bonavides reforça a necessidade de novos métodos hermenêuticos, compreendendo que os anteriores não suprem a necessidade do novo ordenamento jurídico, assim como não observam os aspectos sociais, ideológicos e políticos que nortearam a nova estrutura das constituições:

Os métodos clássicos de interpretação exerceram um influxo inovador mínimo com respeito ao alargamento material da Constituição, por se prenderem de preferência aos quadros fechados da norma juridica, sem um salto mais ousado para o sistema, cujos fins, na época do liberalismo, se compadeciam valorativamente, ou seja, ideologicamente, com esse conhecimento restrito da norma, vista por seu exclusivo teor jurídico (BONAVIDES, 2008, p. 466).

Desse modo, Reis e Dias (2012) elucidam que a nova hermenêutica constitucional busca se libertar dos pressupostos pragmáticos comuns ao regime político liberal. Ela se desprende da percepção de que os fatos e textos jurídicos são essencialmente irreversíveis, implicando numa constante revisão dos preceitos normativos empreendidos sobre uma ação determinante das práticas 
jurídicas. Busca-se assim uma interpretação rizomática das práticas e fazeres jurídicos, dissipando contextos efetivos da atividade legisladora.

Desprende-se, portanto, da hermenêutica clássica, que idealiza a apropriação de valores centralizados na prática do legislador, o que dificultava a compreensão real do significado das normas, propondo-se a sumarização dos sentidos e desejos de investir em algo mais fluido e compreendido de maneira menos pragmática.

Para Alemão (2014), a nova hermenêutica se divide em algumas propostas metodológicas, sendo elas delineadas a partir do: método tópico-problemático; método hermenêutico-concretizador; método científico-estrutural; e método normativo-estruturante. Diante desses métodos, enxerga-se neste artigo uma aproximação com a perspectiva analítica normativa-estruturante, sendo adotada uma visão sobre as tratativas neoconstitucionais.

Como observado, a nova hermenêutica constitucional é capaz de interpretar para além dos textos normativos. Nessa proposta, os princípios constitucionais e os contextos sociais são basilares para a compreensão coerente diante do caso concreto. Dessa forma, a nova hermenêutica constitucional é instrumento capaz de suprir possíveis lacunas do ordenamento jurídico.

Nessa perspectiva, o autor Paulo Bonavides (2004, p. 140) afirma que:

Enquanto os tribunais insistirem em interpretar a lei com métodos especificamente jurídicos, da metodologia clássica, surgidos do dedutivismo jusprivatista inspirado nos cânones de Savigny, eles jamais interpretarão a Constituição. Interpretá-la requer em face da complexa conjuntura social contemporânea a adoção de uma hermenêutica de princípios.

Por almejar que os princípios constitucionais sejam supridos, a nova hermenêutica é fundamental para a efetivação do devido processo legal. Através dessa ciência, é possível agregar nas interpretações dos textos constitucionais e infraconstitucionais o contexto social, além de incluí-lo como objeto de interpretação com a finalidade de compreender de maneira mais coerente o fato ou solucionar conflitos tutelados pelo Judiciário.

A necessidade da compreensão do contexto social atribui ao hermeneuta uma busca incessável de acompanhar as mudanças sociais, que são constantes. É fato que a sociedade não permanece inata, e um advento que deixou as relações sociais mais dinâmicas é a globalização. Esse movimento deu origem à transnacionalidade, que, como observado anteriormente, são relações que perpassam as fronteiras nacionais. 
Há uma grande dificuldade de se tutelar as relações transnacionais. Uma dessas dificuldades é a soberania nacional. A Constituição una ou mundial não se faz viável diante do importante princípio que é a soberania nacional, assim como fragiliza a soberania de outros países caso haja a criação de textos legais nacionais que exerçam influência sobre outros territórios.

Oportuno se faz recorrer às ideias de Philip Jessup (1965) ao tratar sobre o tema direito transnacional. Para este expoente autor, a perspectiva da evolução do homem e, concomitantemente, a necessidade de positivação das novas situações geram uma complexa e numerosa normatividade. Entretanto, o autor afirma que não é necessária, para a solução de todos os conflitos, a instauração de uma lei, afirmando que: “Um problema pode ser solucionado não pela aplicação da lei (embora tampouco pela violação), mas por um método de acordo - meio extralegal ou metajurídico" (p. 15).

A incidência da forma de resolução de lides para além da normatividade é reflexo do sistema common law, que não limita ao magistrado uma atuação meramente legal. Houve um avanço e difusão desse sistema com o advento do neoconstitucionalismo. Como relatado anteriormente, o neoconstitucionalismo permite uma flexibilização da atuação do Poder Judiciário, o qual se pode fazer valer de ferramentas de interpretação e analogia, como é o caso da utilização da hermenêutica.

A partir da instauração do Estado Democrático Moderno, os mesmos operadores do direito oriundos de sistemas caracterizados como civil law passaram a atuar de forma muito próxima do commom law (GUERRA, 2009). Tal contexto permite a participação mais ativa dos magistrados, já que estes possuem um lastro de atuação que lhes confere poderes instrutórios e decisões frente ao contexto social, político e processual.

Nessa perspectiva, pode-se relacionar a influência do neoconstitucionalismo e da transnacionalidade na atuação da nova hermenêutica. 0 Estado Constitucional Moderno é oriundo do neoconstitucionalismo, e tal organização estatal permite uma atuação mais ampla por parte dos magistrados e a utilização de ferramentas para a solução de lides que não se limitam à normatividade, e abrange, por exemplo, a nova hermenêutica, pois uma primazia desse Estado é a busca por efetivação principiológica dentro do contexto social. Ao mesmo tempo, a transnacionalização é um fenômeno que atinge o Estado Constitucional Moderno, já que esse vem fragilizando a soberania deste.

Logo, o Estado Constitucional Moderno deve acompanhar as mudanças sociais e as novas relações que são frutos da transnacionalidade, visto que se propõe a resguardar os anseios e necessidades sociais; somado a isso, ao sistema jurídico é incumbida a solução de lides. Dessa forma, a transnacionalização não 
deve ser vista como um fenômeno negativo, mas como uma consequência da atual conjuntura global, social e política.

Diante disso, a nova hermenêutica constitucional é um remédio necessário para harmonizar os conflitos e as relações transnacionais, em especial, a transnacionalização do direito. Tal ciência, por ter como base a Constituição nacional e o contexto social no qual as partes estão inseridas, compreenderá em suas interpretações uma coerência entre os nacionais de distintos países sem que haja a perda da soberania nacional por ambos, pois, ao magistrado, é permitida uma flexibilização de ferramentas para a solução de lides processuais.

\section{Conclusão}

O movimento neoconstitucionalista atribuiu às constituições novas características e finalidades. A inclusão das necessidades da população como um dos seus princípios fundamentais é o marco que distingue as constituições pré e pós-neoconstitucionalismo. O poder constituinte se tornou responsável por incluir na Constituição dispositivos capazes de proteger e garantir direitos à população. Esses direitos e garantias são denominados direitos fundamentais.

A preocupação com a garantia dos direitos humanos surge após a Segunda Guerra Mundial, diante das atrocidades que ocorreram nesse período. Com a finalidade de evitar novos acontecimentos como os vistos nessa guerra, os Estados positivaram o acordo internacional dos direitos humanos e os inseriram nos textos constitucionais como direitos fundamentais.

Essa positivação é necessária visto que a carta constitucional rege o ordenamento jurídico de determinado Estado, respeitando a soberania nacional. Tal soberania permite que os países possam tutelar, por meio do seu ordenamento jurídico, de forma independente de outros Estados, as relações sociais e as lides presentes no contexto populacional.

Embora deva o ordenamento jurídico tutelar relações, seja por meio de normas constitucionais ou infraconstitucionais, é compreensível que ainda haja lacunas no que se refere a temas específicos, recentes e de pouca repercussão. Esse fato não minimiza a importância daquele, pois se trata, no caso brasileiro, de um ordenamento denso e complexo por abordar distintas searas, mas que ainda assim não consegue ser completo.

O grande desafio do ordenamento jurídico é, assim, a rápida mudança que ocorre na sociedade. A mutabilidade social contínua torna a tarefa do legislador cada vez mais difícil, pois não há como acompanhar essas vicissitudes. Em outras palavras, diante dessa complexidade não é tarefa fácil a criação de dispositivos 
que alberguem todas as novas relações e todos os novos contextos sociais em que a população está inserida.

As lacunas oriundas do ordenamento jurídico podem ser preenchidas através da abordagem hermenêutica, por esta se tratar de uma ciência capaz de solucionar divergências normativas e fundamentar decisões. É fato que a hermenêutica jurídica clássica já não consegue dar cabo a essas lacunas. A proposta da nova hermenêutica constitucional se apresenta como um instrumento necessário por não somente observar a normatividade, mas por ser guiada pelos princípios constitucionais diante dos contextos culturais, sociais e ideológicos transnacionais. Nessa perspectiva, é possivel observar a relação intrínseca entre o neoconstitucionalismo e a nova hermenêutica constitucional: a preocupação com o contexto social vigente.

No que concerne à busca pela tutela das relações sociais e à sua mutabilidade contínua, há uma peculiaridade, qual seja, a globalização. Esse fenômeno proporcionou novos vínculos entre pessoas, empresas de nações distintas e até relações entre diferentes Estados soberanos. No seio do movimento globalização surge a transnacionalização, uma fenomenologia que aparece a partir do novo âmbito econômico-comercial.

A transnacionalização, embora inicialmente vista apenas sob a ótica mercantil, também passou a influenciar os ordenamentos jurídicos mundiais e, consequentemente, as soberanias estatais. As decisões, na perspectiva econômica, produziram efeitos diretos nas dimensões política e social. Assim, a desterritorialização das relações econômicas, políticas e sociais compreende a transnacionalidade.

A interferência social oriunda do reflexo da nova perspectiva da ordem econômica mundial implica diretamente no campo do direito, visto que este é instrumento fundamental para regulamentar as relações sociais e também econômicas. Ao compreender a transnacionalidade do direito como capaz de envolver toda a regulação de ações ou eventos que ultrapassam fronteiras nacionais, questiona-se sobre a fragilização da soberania nacional.

A soberania nacional é de suma importância para o bom desenvolvimento estatal, pois é por meio desta que é possível regular e ordenar as ações e relações que ocorrem no âmbito territorial. Nesse diapasão, há o questionamento sobre a invencibilidade da soberania, mas é necessário observar que, embora haja a fragilização legal do Estado, este não desapareceu.

Essa tensão entre a necessidade de regular as relações transnacionais sem que haja a perda da soberania estatal pode ser solucionada através da utilização da nova hermenêutica constitucional, que preserva os princípios constitucionais oriundos do movimento neoconstitucional, preocupa-se com o contexto social das 
partes e não fragiliza de forma excessiva a soberania por não necessitar de novos dispositivos legais, e sim uma interpretação coerente entre as partes localizadas em países distintos, sem que haja o desfavorecimento de um Estado em relação ao outro.

\title{
The influence of transnationalization of law and neoconstitutionalism on the new constitutional hermeneutics
}

\begin{abstract}
Globalization has stimulated several changes in technology, economics and politics, directly influencing social relations and, consequently, guiding the state's performance. Transnationalization, in turn, is a phenomenon that leads to the overcoming of national borders. In this respect, in a global world with transnational public and private corporations, inevitably, complex problems of different shades arise, especially in terms of interpretation of the national and foreign legal norm, which justifies the urgent need to study and deepen the subject. In view of these premises, this article analyzes the importance of the new hermeneutics for the resolution of conflicts arising from the transnationalisation of Law, in times of globalization, without weakening the principles of the neoconstitutionalism movement. In order to do so, through bibliographical research, concepts are taken up, in a historical perspective of different doctrinators about transnationalization, hermeneutics and neo-constitutionalism. Moreover, the paper analyzes the challenges of law and neo-constitutionalism in the face of the complexities of society without frontiers, and advocates the relevance of hermeneutics to the legal order as an instrument for resolving transnational conflicts.
\end{abstract}

Keywords: Transnationalization. Neo-constitutionalism. New constitutional hermeneutics.

Summary: 1 Introduction - 2 Historical perspective of globalization and its impact on transnational relations and state sovereignty - 3 Neo-constitutionalism and the constitutional challenges of globalization - 4 The relevance of hermeneutics to the legal order as an instrument for resolving transnational conflicts - $\mathbf{5}$ Conclusion - References

\section{Referências}

ACCIOLY, Hidelbrando. Tratado de Direito Internacional Público. Rio de Janeiro, 1954.

AGUADO, Juventino de Castro. As Novas Formas do Estado e do Direito em Tempos de PósModernidade (Estado Constitucional - Uma Visão Sócio-Jurídica do Poder). Revista Nacional de Direito e Jurisprudência. n. 81, ano 7, set. 2006.

ALDUNATE LIZANA, Eduardo. Aproximación conceptual y crítica al neoconstitucionalismo. Revista de derecho (Valdivia), v. 23, n. 1, p. 79-102, 2010.

BARROSO, Luiz Roberto. Neoconstitucionalismo e constitucionalização do direito. O triunfo do direito constitucional no Brasil. Revista da Escola Nacional da Magistratura, Brasília, Escola Nacional da Magistratura, a. I, n. 2, 2006.

BECK, Ulrich. O que é globalização? Tradução de André Carone. São Paulo: Paz e Terra, 1999. 
BOBBIO, Norberto. O positivismo jurídico. Lições de filosofia do direito. Compilação pelo Dr. Nello Morra. Tradução e notas de Márcio Pugliesi, Edson Bini e Carlos E. Rodrigues. São Paulo: Editora Ícone, 2006.

BOBBIO, Norberto; MATTEUCCI, Nicola; PASQUINO, Gianfranco. Dicionário de Política. Tradução de João Ferreira, Carmen Varriale et al. Brasília: UnB, 1986.

BONAVIDES, Paulo. Curso de Direito Constitucional. 10. ed. São Paulo: Malheiros, 2000.

BONAVIDES, Paulo. Curso de Direito Constitucional. 23. ed. São Paulo: Editora Malheiros, 2008.

BONAVIDES, Paulo. Jurisdição constitucional e legitimidade (algumas observações sobre o Brasil). Estudos avançados, v. 18, n. 51, p. 127-150, 2004.

BRAILLARD, Philippe. Teoria das Relações Internacionais. Tradução de J. J. Pereira Gomes c A. Silva Dias. Lisboa: Fundação Calouste Gulbenkian, 1979.

CANOTILHO, José Joaquim Gomes. Direito constitucional e teoria da constituição. Reimpressão da 7. ed. Coimbra: Almedina, 2017.

CRUZ, Paulo Márcio; BODNAR, Zenildo. A transnacionalidade e a emergência do estado e do direito transnacionais. In: CRUZ, Paulo Márcio; STELZER, Joana (Org.). Direito e transnacionalidade. Curitiba: Juruá, 2010.

CUNHA, Rômulo Silva. A constituição num mundo globalizado. 2010. Âmbito Jurídico, Rio Grande, XIII, n. 74. Disponível em: <http://www.ambito-juridico.com.br/site/index.php?n_ link=revista_artigos_leitura\&artigo_id=7281>. Acesso em: 17 jan. 2017.

DALLARI, Dalmo de Abreu. Elementos de teoria geral do Estado. 25. ed. São Paulo: Saraiva, 2005.

FARIA, José Eduardo. O direito na economia globalizada. São Paulo: Malheiros, 2002.

FERNANDES, Rodrigo; SANTOS, Rafael Padilha dos. Transnacionalidade e os novos rumos do Estado e do Direito. Revista Eletrônica Direito e Política, Programa de Pós-Graduação Stricto Sensu em Ciência Jurídica da UNIVALI, Itajaí, v. 9, n. 1, 2014. Disponível em: <www. univali.br/direitoepolitica>. Acesso em: 19 dez. 2016.

FONTENELE JÚNIOR, Ubirajara Souza. A hermenêutica jurídica clássica e a hermenêutica jurídica constitucional . Revista Jus Navigandi, Teresina, ano 19, n. 4032, 2014. Disponível em: <https://jus.com.br/artigos/28873>. Acesso em: 9 fev. 2017.

FRANÇA, R. Limongi. Hermenêutica jurídica. 9. ed. São Paulo: Revista dos Tribunais, 2009.

GRAU, Eros Roberto. O direito posto e o direito pressuposto. 8. ed. rev. amp. São Paulo: Malheiros, 2011.

GUERRA, Marcel Vitor de Magalhães et al. Nova Hermenêutica das Normas de Competência Internacional: Incompatibilidade do Modelo Rígido Novos Estudos Jurídicos, v. 14, n. 3, p. 23-39, 2009.

HÄBERLE, Peter. Novos Horizontes e Novos Desafios do Constitucionalismo. Revista LatinoAmericana de Estudos Constitucionais, Belo Horizonte: Ed. Del Rey, 2007. 
HÄBERLE, Peter, J. Hermenêutica constitucional - a sociedade aberta dos intérpretes da constituição: contribuição para interpretação pluralista e "procedimental" da constituição. DPU, n. 60, p. 25-50, 2014. Disponível em: <https://www.portaldeperiodicos.idp.edu.br/ direitopublico/article/view/2353/1204>. Acesso em: 28 jan. 2018.

JESSUP, Philip C. Direito Transnacional. Tradução de Carlos Ramires Pinheiro da Silva. São Paulo: Fundo de Cultura, 1965.

$\mathrm{KOH}$, Harold Hongju. Why Transnational Law Matters. Faculty Scholarship Series. Paper 1793. Yale Law School Legal Scholarship Repository. HeinOnline - 24 Penn St. Int'I L. Rev. 752 2005-2006. Disponível em: <http://digitalcommons.law.yale.edu/fss_papers/1793>. Acesso em: 28 fev. 2017.

LIMA, Renata Albuquerque. A atuação do estado brasileiro e a crise empresarial na perspectiva da lei de falências e de recuperação de empresas. Rio de Janeiro: Lumen Juris, 2014.

MAXIMILIANO, Carlos. Hermenêutica e aplicação do Direito. 19. ed. Rio de Janeiro: Forense, 2008.

MAZZUOLI, V. O. O controle jurisdicional de convencionalidade das leis. 3. ed. São Paulo: Revista dos Tribunais, 2013.

MEDEIROS, Morton Luiz Faria de. A clareza da lei e a necessidade de o Juiz interpretá-la. Revista de Informação Legislativa, a. 37, n. 146, abr./jun. 2000.

MIRANDA, Jorge. Manual de Direito Constitucional. 4. ed. Coimbra: Coimbra Editora, 2000.

NUNES, Antonio José Avelã. Aventuras e desventuras do Estado Social. Revista da Fundação Brasileira de Direito Econômico, v. 3, 2011.

ONU. Organização das Nações Unidas. Carta das Nações Unidas, 1945.

PASOLD, Cesar Luiz; FERRER, Gabriel Real; CRUZ, Paulo Márcio. Reflexões sobre o futuro do Estado Constitucional Moderno. Revista Brasileira de Políticas Públicas, v. 6, n. 1, 2016.

PEÑA DE MORAES, Guilherme. Direito constitucional: teoria da Constituição. 2. ed. Rio de Janeiro: Lumen Juris, 2004.

REIS, J. R.; DIAS, F. V. A hermenêutica como substrato aos conflitos de direitos fundamentais: liberdades comunitárias vs. direitos de personalidade. Revista de Estudos Constitucionais, Hermenêutica e Teoria do Direito, v. 4, n. 1, p. 65-80, 2012.

ROSA, Alexandre Morais. Direito Transnacional, soberania e o discurso da Law and Economics. Direito e transnacionalidade, Curitiba: Juruá, 2011.

SARMENTO, Daniel. Interpretação Constitucional, Pré-Compreensão e Capacidades Institucionais do Interprete. In: SOUZA NETO, Claudio Pereira de; BINEMBOJN, Gustavo; SARMENTO, Daniel (Orgs.). Rio de Janeiro: Lumen Juris, 2009.

SARMENTO, Daniel. Ubiqüidade Constitucional: Os Dois Lados da Moeda. In: SOUZA NETO, Cláudio Pereira de; SARMENTO, Daniel (Coords.). A Constitucionalização do Direito: Fundamentos Teóricos e Aplicações Específicas. Rio de Janeiro: Lumen Juris, 2007.

SILVA, José Afonso da. Curso de direito constitucional positivo. rev. e atual. Até a Emenda Constitucional n. 76, de 28.11.2013. 37. ed. São Paulo: Malheiros, 2014. 
SILVA, Juliana Giovanetti Pereira da; ANTUNES FILHO, Apolo; DOVIZIO, Paula Treges. O neoconstitucionalismo na pós-modernidade. In: Âmbito Jurídico, Rio Grande, XVII, n. 128. 2014. Disponível em: <http://ambitojuridico.com.br/site/?n_link=revista_artigos_ leitura\&artigo_id=15175>. Acesso em: dez. 2016.

SILVA, Kelly Suzane Alflen da. Interpretação e Concretização Normativo-Constitucional. Revista Direito Público, n. 27, 2009, p. 46-47. Disponível em: <http://www.direitopublico.idp.edu. br/index.php/direitopublico/issue/view/56>. Acesso em: 02 fev. 2017.

SILVA, Karine de Souza. A consolidação da União Européia e do direito comunitário no contexto da Transnacionalidade. In: CRUZ, Paulo Márcio; STELZER, Joana (Org.). Direito e transnacionalidade. Curitiba: Juruá, 2010.

SLAIBI FILHO, Nagib. Hermenêutica Constitucional. Disponível em: <http://elerj.files. wordpress.com/2011/08/hermenc3aautica_constitucional.pdf>. Acesso em: 28 nov. 2016.

SOARES, Andrea Ântico; RIGOLDI, Viviane. O Constitucionalismo do Futuro de José Roberto Dromi: Questões acerca da viabilidade de um Constitucionalismo Universal. Revista Univem, 2013. Disponível em: <http://revista.univem.edu.br/index.php/emtempo/article/ viewFile/411/328> Acesso em: 20 dez. 2016.

STELZER, Joana. O fenômeno da transnacionalização da dimensão jurídica. Direito e transnacionalidade, Curitiba: Juruá, 2011.

TORRES, Claudia Vechi; SILVA, Maria dos Remédios Fontes. Hermenêutica constitucional: avanços e desafios na sociedade contemporânea. Publica Direito - UFSC. 2014. Disponível em: <http://www. publicadireito.com.br/artigos/?cod=4a7ad6a4dfd49733>. Acesso em: 03 fev. 2017.

VIEIRA JÚNIOR, Dicesar Beches. Neoconstitucionalismo: Definição, crítica e concretização dos direitos fundamentais. Revista Constituição e Garantia de Direitos, v. 6, n. 02, 2014.

Informação bibliográfica deste texto, conforme a NBR 6023:2002 da Associação Brasileira de Normas Técnicas (ABNT):

LIMA, Renata Albuquerque; MAGALHÃES, Átila de Alencar Araripe; DIAS, Thaís Araújo. A influência da transnacionalização do direito e do neoconstitucionalismo na atuação da nova hermenêutica constitucional. Direitos Fundamentais \& Justiça, Belo Horizonte, ano 12, n. 38, p. 307-331, jan./jun. 2018.

Submetido: 28.02 .2018

Pareceres: 11.05.2018, 24.05.2018

Aprovado: 24.05.2018 